\title{
OS IMPACTOS AMBIENTAIS DA PONTA SERRA REGISTRO DAS ATIVIDADES COM O AUXÍLIO DO LAPTOP EDUCACIONAL
}

\author{
Maria Tatiane Lima de Oliveira ${ }^{1}$, Karla Angélica Silva do Nascimento ${ }^{2}$, José Aires \\ de Castro Filho ${ }^{2}$
}

${ }^{1}$ Escola de Ensino Médio Joaquim Valdevino de Brito. Caixa Postal: 63138-000 - Ponta da Serra - Crato - CE - Brasil

${ }^{2}$ Instituto UFC Virtual - Universidade Federal do Ceará (UFC). Caixa Postal: 60440554 - Fortaleza - CE - Brasil

tatiolvr@hotmail.com, \{karla,aires\}@virtual.ufc.br

\begin{abstract}
This study is justified by the importance and need to know how the population living near the school has been treating the environment. Aims to identify the digital resources used during the activities of the Project Environmental Impacts in the district Ponta da Serra. With the laptop, students photographed the devastated regions and made notes about the types of risk elements spot on Google Maps. The results show that the work met the didactic objectives, as promoted student interest in identifying and recording the causes and consequences of environmental impacts around the school with collaborative map as well as stimulated the creation of proposals to mitigate existing damage and prevent future.
\end{abstract}

Resumo. Este estudo se justifica pela importância e necessidade de se conhecer como a população residente próximo a escola vem tratando o meio ambiente. Tem como objetivo identificar os recursos digitais usados durante as atividades do Projeto Impactos Ambientais no distrito Ponta da Serra. Com o laptop, os alunos fotografaram as regiões devastadas e fizeram anotações sobre os tipos de elementos de riscos in loco no Google Maps. Os resultados mostram que o trabalho realizado cumpriu os objetivos didáticos, pois promoveu interesse dos alunos em identificar e registrar as causas e consequências dos impactos ambientais no entorno da escola com mapa colaborativo, bem como estimulou a criação de propostas para amenizar os danos existentes e prevenir futuros.

\section{Introdução}

De tempos em tempos, a ciência e a sociedade elegem determinados temas como objeto preferencial de ação, reflexão e debate, de acordo com a necessidade do tempo em questão. Um discurso de forte apelo cultural é aquele associado ao tópico ambiental, haja vista que esse assunto é de fundamental importância, principalmente nas escolas, para conscientização do cuidado com o meio ambiente.

São inúmeros os impactos causados pelo desenvolvimento da sociedade nesses últimos séculos. Desmatamento desenfreado, urbanização desregulada, uso inapropriado 
dos recursos naturais, segregação social e espacial, grandes guerras mundiais, uso de armas químicas e biológicas, acidentes nucleares, poluição de grandes rios, impermeabilização do solo, uso inadequado da água e do solo, enfim, todo um conjunto de fatores globais visando o desenvolvimento econômico que criou uma paisagem em desconformidade com o meio ambiente natural.

A denominada crise ambiental, a que hoje assistimos, padece dessa situação e deve suscitar uma revisão das teorias e práticas trabalhadas em diversas disciplinas escolares. Dessa forma, é preciso fazer uma análise desse enfoque em escala local, visando um aprofundamento desses fatores de riscos ao meio ambiente e que estão ligados diretamente a nós, sobretudo em nossas comunidades. Neste sentido, utilizamos alguns recursos digitais que com ajuda do laptop educacional fornecem informações, comunicação e colaboração dos alunos nas aulas de Geografia. Conforme Nascimento (2011), a necessidade de utilizar recursos digitais na educação está atrelada às demandas da sociedade, devendo-se saber como, por que e onde devem ser usados.

Com base nessas inquietações, apresentamos a questão que norteia esta pesquisa: como e quais recursos digitais podem ser utilizados nas aulas de Geografia para entender, identificar, registrar e divulgar os impactos ambientais no distrito de Ponta da Serra com o auxílio do laptop educacional? Esse artigo tem como objetivo identificar os recursos digitais usados durante as atividades do Projeto Impactos Ambientais no distrito Ponta da Serra. O presente trabalho está organizado da seguinte maneira: no segundo tópico apresentamos o tema trabalhado nas aulas e como o laptop e os recursos digitais foram utilizados durante o desenvolvimento do projeto; no terceiro descrevemos os métodos para a coleta de dados; no quarto tópico expomos os resultados e, por último, as considerações finais.

\section{Estudo sobre os impactos ambientais nas aulas de Geografia e o laptop educacional}

O acentuado processo de crescimento e desenvolvimento ocorrido nas últimas décadas no Brasil possui como uma das principais características, além do aumento da densidade populacional e de construções, um completo alijamento das questões sociais, econômicas e políticas que influenciam diretamente no meio ambiente.

O meio ambiente é um tema local e global que necessita da atenção da sociedade. A forma errada de exploração dos recursos naturais ao longo de anos tem gerado consequências difíceis de lidar. Portanto, em busca de minimizar os efeitos negativos da intervenção humana sobre a natureza, práticas baseadas na, informação, preservação e na recuperação devem ser inseridas em nosso cotidiano.

Para que os alunos se sintam sensibilizados com o tema é necessário que o professor também manifeste o desejo e a preocupação de preservar o lugar onde vive. É nesse contexto que a educação ambiental age, preparando crianças e, principalmente, jovens do Ensino Médio, para se posicionarem diante dos desafios atuais e futuros decorrentes dessa questão. Nas escolas, esse tema é trabalhado de forma transversalizada, e pode render bons resultados se o professor usar, além da criatividade, materiais especializados sobre o assunto e adequados para essa faixa etária.

Dessa forma, os Parâmetros Curriculares Nacionais propõem que esse tema seja integrado às demais disciplinas, pois assim proporciona uma visão abrangente do tema, ou seja, a perspectiva ambiental deve levar os alunos à reflexão sobre os 
problemas que afetam a sua vida, a de sua comunidade, a de seu país e a do planeta. Isso significa que:

Espera-se que a escola contribua para a constituição de uma cidadania de qualidade nova, cujo exercício reúna conhecimentos e informações a um protagonismo responsável, para exercer direitos que vão muito além da representação política tradicional: emprego, qualidade de vida, meio ambiente saudável, igualdade entre homens e mulheres, enfim, ideais afirmativos para a vida pessoal e para a convivência [Brasil 2000, p.18].

Citamos por exemplo a escassez de água, que é uma preocupação mundial, mas percebida em proporções peculiares, principalmente na comunidade local em questão. É importante compreender como o ser humano vem adotando práticas de vida que só contribuem para o desenvolvimento desse problema. Nessa mesma perspectiva Santos [2006, p.29], em seu livro "Por uma outra globalização", analisa o papel do cidadão frente ao meio ambiente, relacionado ao consumismo desenfreado. Para ele,

Consumismo e competividade, levam ao emagrecimento moral e intelectual da pessoa, à redução da personalidade e da visão do mundo, convidando, também, a esquecer a oposição fundamental entre a figura do consumidor e a figura do cidadão. É certo que no Brasil tal oposição é menos sentida por que em nosso país jamais houve a figura do cidadão.

O autor assegura que o problema ambiental tem raízes na má formação da cidadania, em especial, a população brasileira. Neste sentido, é no atual processo de globalização que o discurso ambiental assume papel fundamental, principalmente no uso das Tecnologias de Informação e Comunicação (TIC) que promovem a sustentabilidade social ao proporcionar novas possibilidades de acesso a serviços e de participação na comunidade.

Essas tecnologias promovem troca de informação e comunicação e compartilhamento de conhecimentos que podem influenciar um grupo de pessoas ou uma comunidade inteira. A partir desse contexto, os alunos do Ensino Médio da Escola $\mathrm{X}$, localizada no próprio distrito e contemplada com o Projeto UCA, estudaram os elementos socioambientais, econômicos e políticos da região em que vivem.

Dentre os princípios do Projeto UCA, ressaltamos: a exploração pedagógica da mobilidade do laptop educacional; a formação de comunidades de aprendizagem; a interação entre as pessoas e a construção coletiva do conhecimento; a promoção de letramentos, não somente relacionados à leitura, escrita ou digital, mas à visual e sonora; integração do laptop educacional ao currículo escolar; apropriação das TIC; e a constituição de redes de construção coletivas, nas quais professores e alunos poderão explorar diferentes alternativas de ensino e aprendizagem [Brasil 2009].

Com o auxílio do laptop educacional e o acesso a Internet, os alunos podem buscar informações sobre temas geoambientais nas aulas, investigar questões relacionadas à desigualdade entre países ricos e pobres, caracterizar urbanidade e ruralidade e identificar as diferenças de desenvolvimento econômico entre classes sociais.

O objeto deste estudo está voltado para os impactos ambientais de um distrito, cuja área rural possui características normais, porém vem sofrendo devastação em sua estrutura ambiental [Lima 2011]. Veremos a seguir os procedimentos metodológicos realizados no trabalho. 


\title{
3. Contexto e metodologia
}

A abordagem metodológica adotada é de natureza qualitativa e foi composta por dois momentos distintos: 1) identificação dos conhecimentos prévios dos alunos acerca do tema impactos ambientais; 2) soluções encontradas para prevenir os impactos na região.

A Escola X está situada em uma zona rural do distrito de Ponta da Serra a 13 $\mathrm{km}$ do município do Crato no Ceará, e funciona nos turnos manhã, tarde e noite. A escola conta com aproximadamente 500 alunos distribuídos em 13 turmas do Ensino Médio, 24 professores e uma equipe gestora composta por uma diretora e dois coordenadores pedagógicos.

Para iniciar o estudo sobre os impactos ambientais foi necessário fazer um levantamento bibliográfico e cartográfico da região. Nesse momento os alunos utilizaram pesquisas na biblioteca da escola, levantamento de fontes na Internet e estudo sobre o uso das ferramentas de mapeamento dos impactos ambientais.

Após o estudo detalhado sobre o meio ambiente global e local, os alunos buscaram desenvolver medidas que pudessem amenizar ou solucionar os impactos do lugar onde vivem. Dessa forma, elaboraram, junto com a professora de Geografia, um questionário com o intuito de conhecer a fundo os costumes e a forma como a comunidade vem tratando o meio ambiente.

Os alunos se dividiram em equipes e foram a campo para entrevistar vinte famílias residentes no distrito. Além disso, identificaram e registraram, através de fotografias, elementos de degradação e devastação na localidade.

Com o auxílio do laptop educacional os estudantes criaram planilhas eletrônicas no aplicativo Calc para organizar os dados, utilizaram o aplicativo Writer para fazer anotações gerais sobre os fatores de riscos apresentados pelo solo, preencheram o questionário sobre aspectos socioeconômicos das famílias e compararam e geraram gráficos dos dados obtidos na pesquisa.

Essas ações foram acompanhadas e observadas, permitindo a inserção do investigador no ambiente de pesquisa, a fim de se apropriar do contexto do grupo e fazer aproximações com a teoria que embasa a investigação e com seus pontos de vista. Como afirma Chizzotti [1998, p. 90]:

\begin{abstract}
a observação direta pode visar uma descrição "fina" dos componentes de uma situação: os sujeitos em seus aspectos pessoais e particulares, o local e as circunstâncias, o tempo e suas variações, as ações e suas significações, os conflitos e a sintonia de relações interpessoais e sociais, e as atitudes e os comportamentos diante da realidade.
\end{abstract}

Essa coleta de dados, dentro de um estudo qualitativo, representou um processo dinâmico. Desta forma analisamos, a partir do acompanhamento pedagógico, os recursos digitais utilizados, as produções dos alunos, as observações registradas nas aulas, o auxílio do laptop educacional e as soluções encontradas pelos estudantes para melhorar e prevenir ações de degradação no ambiente em que vivem.

A professora que conduziu essas atividades considera que para trabalhar com o laptop educacional é necessário um bom planejamento, orientar cada etapa da tarefa e ter objetivos bem definidos, pois "os alunos precisam saber o que se quer com a tarefa", defende ela. Conforme Zucker (2005) o êxito de projetos com laptops na escola estão vinculados a um conjunto de procedimentos que envolvem quatro aspectos 
fundamentais: planejamento, desenvolvimento profissional, hardware e software, gestão, monitoramento e avaliação. No próximo item apresentamos os resultados encontrados.

\section{Resultados}

No presente tópico expomos os resultados alcançados durante o processo de investigação da pesquisa. Estes foram divididos em dois tópicos principais: uso e ocupação do solo, que expõe o levantamento das percepções dos alunos sobre os impactos ambientais; alternativas ambientais, que apresenta as soluções encontradas para prevenir esses impactos na região.

\subsection{Uso e ocupação do solo}

Com base no registro de fotos, os alunos puderam perceber que as transformações da paisagem são resultantes, sobretudo, das diferentes formas de uso e ocupação do solo associadas ao crescimento populacional e consumo. A questão da sustentabilidade esbarra nos interesses políticos que, em seu projeto de gestão, simplificam a problemática ambiental em detrimento do fator econômico.

Para mapear a região, os alunos usaram a ferramenta Google Maps com o intuito de marcar os pontos de maior degradação no distrito. Assim, foi possível organizar e dividir as tarefas de pesquisa e coleta de dados nas equipes de alunos. Após esse estudo, procuraram identificar o tipo de ocupação do solo, conforme apresentado na Figura 1.

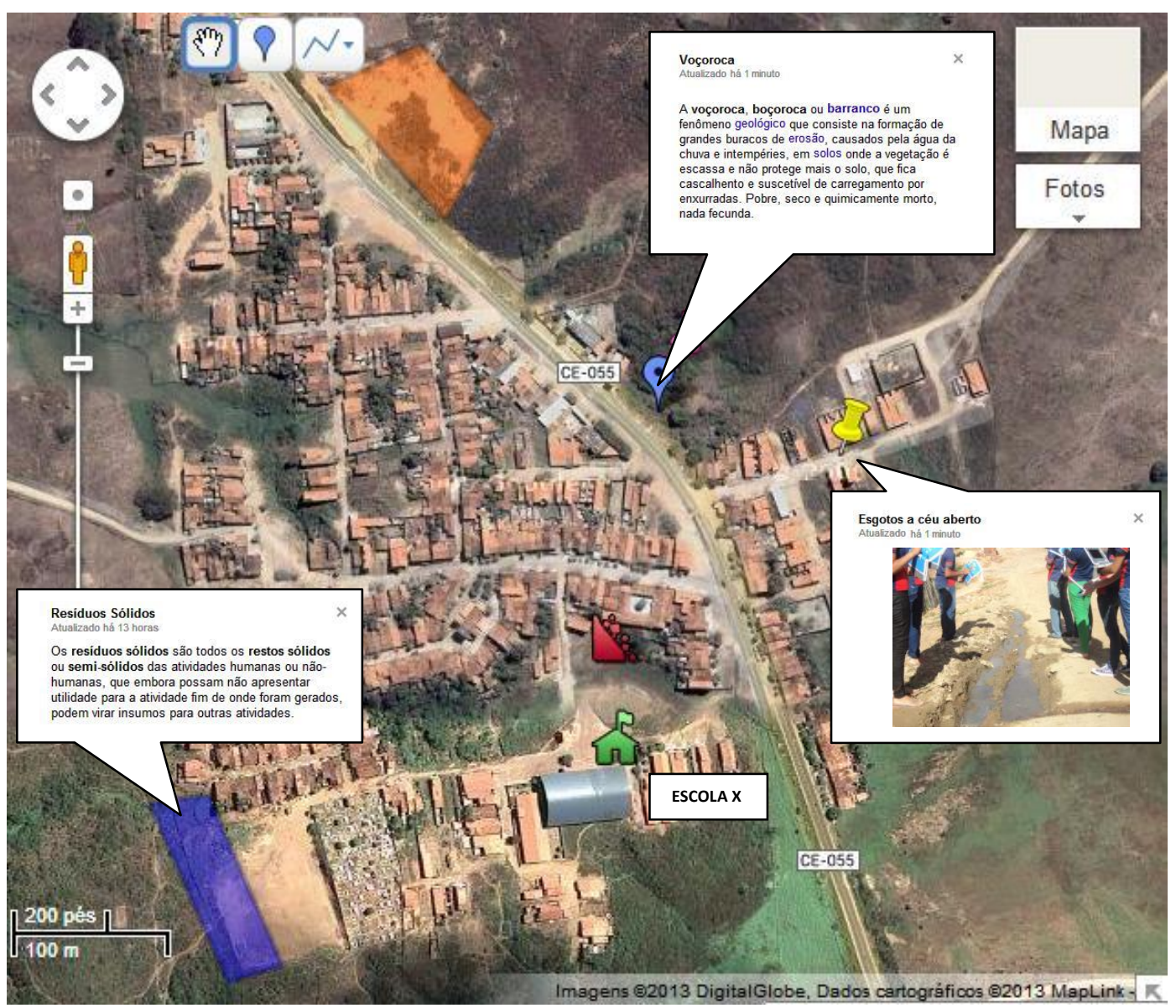

Figura 1. Mapeamento da região para estudo e organização da coleta de dados. 
O Google Maps permite adicionar, editar e armazenar informações, como local de marcadores, linhas, formas, textos, fotos, vídeos, sites e formulários, apresentados na Figura 1. Segundo Ribeiro e Lima [2011, p.44], "tais dispositivos de projeção possibilitam a emergência de processos e vínculos mais próximos com os lugares e consequentemente uma maior possibilidade de produção de significados e de elementos constituintes de novas representações sociais". Uma característica importante é o compartilhamento de dados, que permite aos colaboradores de um mapa partilhar sua criação com outras pessoas ou grupos de pessoas geograficamente separadas.

Ao analisarem as Figuras 2 e 3, fotografias registradas durante a aula de campo, os alunos puderam perceber que se trata de uma comunidade rural e que se desenvolve principalmente a agricultura. Essa região tem como consequência uma devastação da vegetação e erosão do solo. Durante as aulas, os alunos perguntavam: como as pessoas vivem em ruas sujas assim? Porque esses animais convivem com os moradores? Será que podemos fazer algo para mudar essa realidade? Como se formaram essas voçorocas?

Essas inquietações foram primordiais para dar continuidade ao trabalho, pois nos fizeram perceber a dimensão da percepção dos alunos a respeito da temática. É neste sentido que a ciência geográfica deve partir, ou seja, é do questionamento de como, onde, em que época o homem se relaciona com a natureza [Santos 2006].

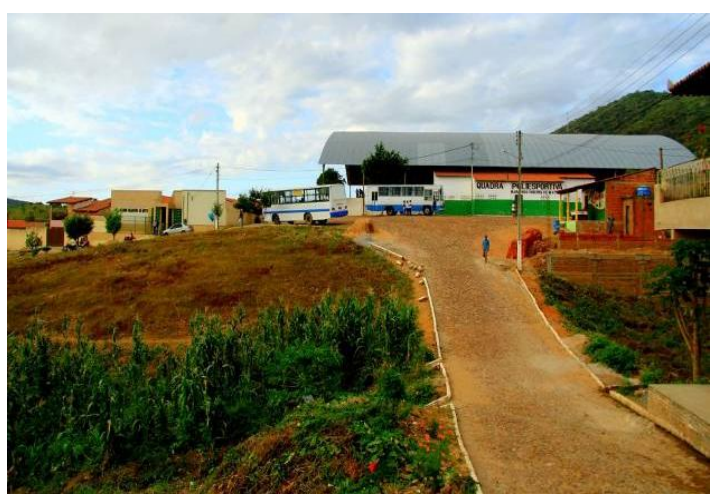

Figura 2. Rua de acesso à escola

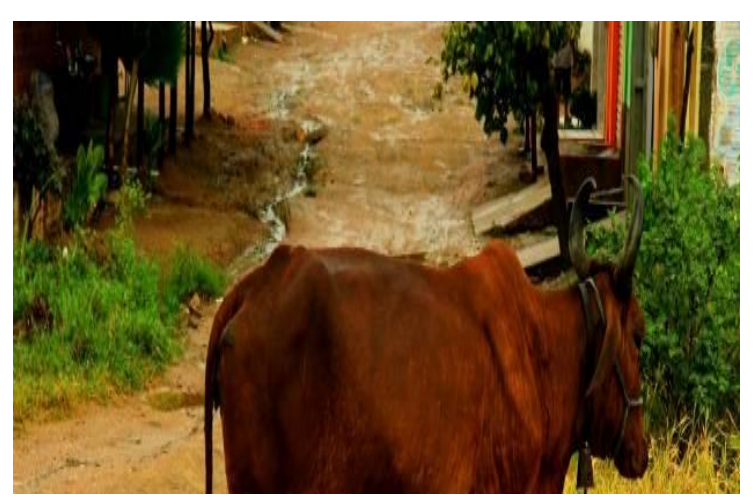

Figura 3. Loteamento Santa Rita de Cássia

Para identificar o relevo da região, os alunos registraram fotos que pudessem avaliar os fatores de ocupação do solo. As Figuras 4 e 5 apresentam um acentuado relevo da região que contribui para ocorrência de deslizamentos e também uma atividade comercial muito utilizada por essa comunidade que consiste na fabricação artesanal de tijolos e telhas, atividade essa que empobrece, erode o solo da localidade.

Por se tratar de uma ocupação em encosta de morros e serras é possível constatar que cada vez mais esse território vem se expandindo por causa das novas construções, principalmente as habitacionais. Desta forma a relação homem natureza não tem se preocupado com o equilíbrio ambiental, revelando cenários ambientalmente degradados em favor da produção [Santos 2006].

Com base nesses elementos foi necessário o conhecimento do contexto histórico atual da região. Neste sentido, focamos o estudo do espaço geográfico, como também entender a relação da sociedade com a natureza, assim, tentamos expor nestas atividades, a escolha da abordagem integrada entre o teórico e a análise de fatos reais. 


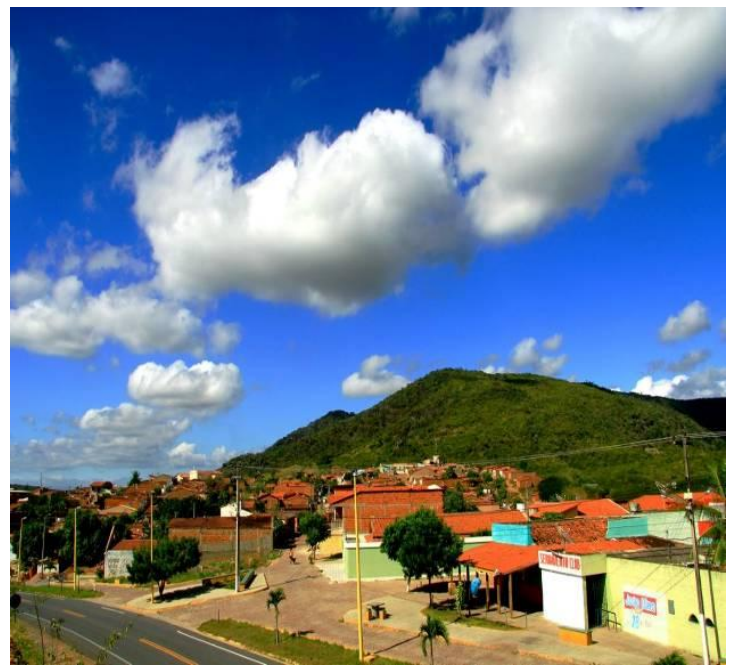

Figura 4. Distrito Ponta da Serra

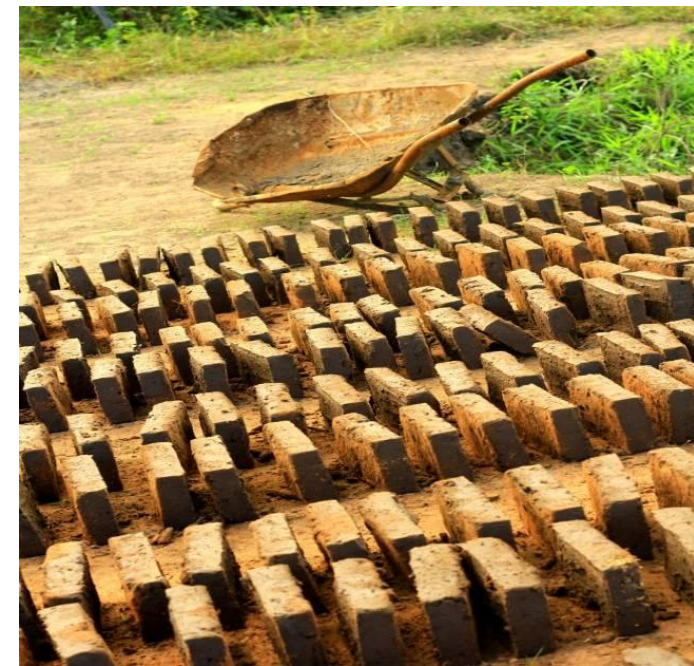

Figura 5. Fabricação de tijolos artesanais

Com respeito aos dados do questionário e criação de gráficos no aplicativo Calc, os alunos avaliaram que o nível econômico da população é muito baixo, $50 \%$ das casas pesquisadas se mantém com apenas um salário mínimo, conforme Gráfico 2. Em relação ao saneamento básico, como apresentado no Gráfico 1, verificaram que $90 \%$ da comunidade utiliza fossa negra, que empobrece e contamina o solo (Figura 6).

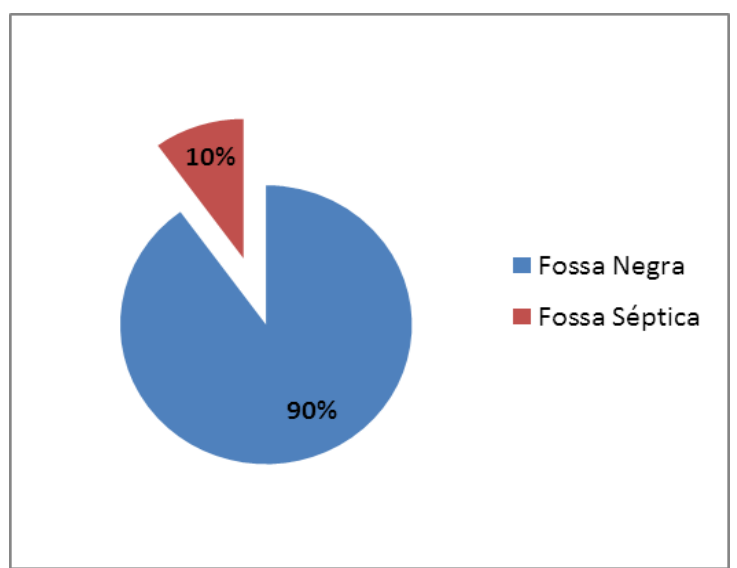

Gráfico 1. Tipos de fossas usadas

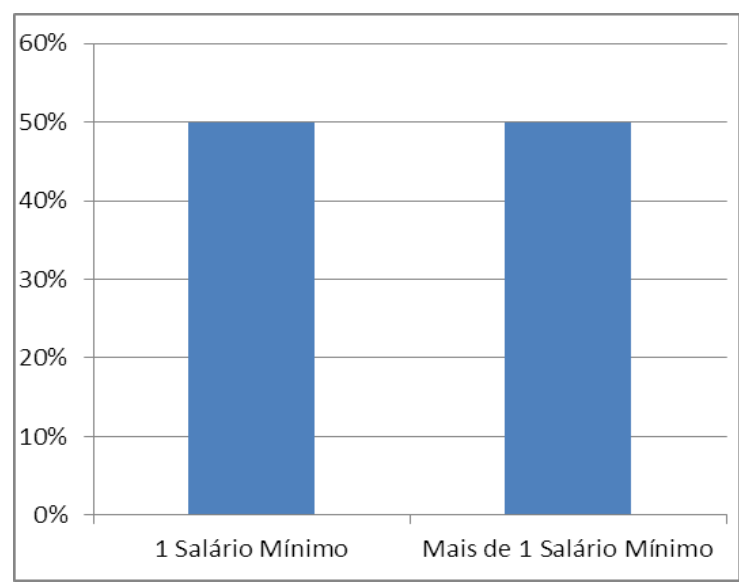

Gráfico 2. Nível econômico da população

Os alunos também observaram que a população dispõe de coleta de lixo regularmente, porém não é seletiva. Este aspecto gerou muita discussão na turma, pois os estudantes, através da pesquisa in loco, perceberam que essa coleta é depositada em um lixão a céu aberto, além disso, muitos moradores também se desfazem do lixo em terrenos baldios, cultura irresponsável, porém comumente praticada, como visualizado na Figura 7. 


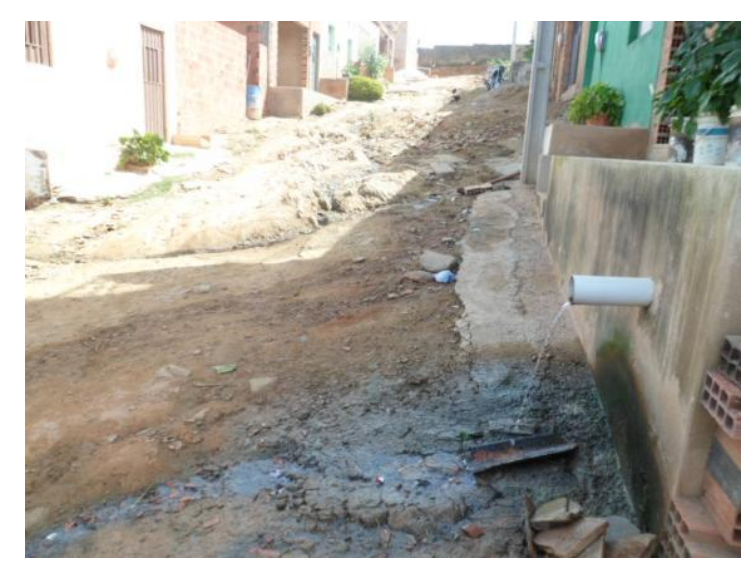

Figura 6. Esgoto a céu aberto

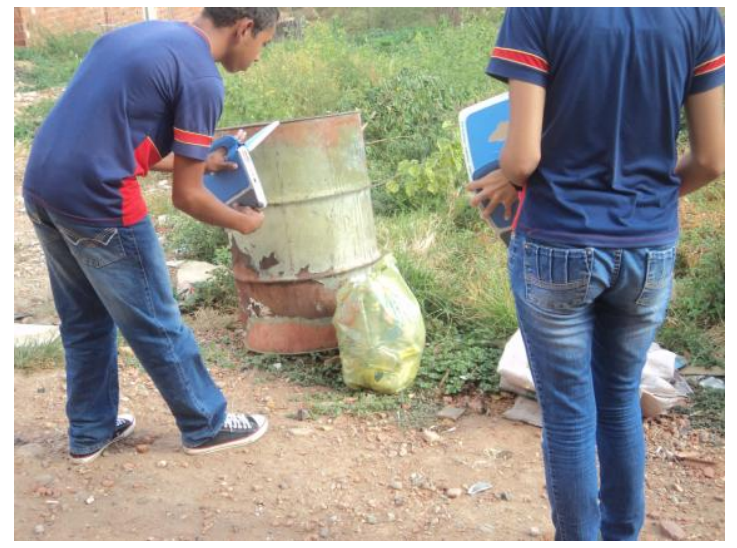

Figura 7. Lixo em terrenos baldios

Após analisados e diagnosticados os problemas ambientais da comunidade no entorno da escola, os alunos apontaram algumas alternativas ambientais para solucionar os problemas que foram anteriormente citados.

\subsection{Alternativas ambientais}

Dentre as possíveis soluções viáveis, os alunos desenvolveram slides no aplicativo Impress, instalado no laptop educacional, e promoveram apresentações dos resultados da pesquisa à comunidade escolar. Assim como, criaram panfletos informando sobre a importância da preservação, da coleta seletiva e da reciclagem do material.

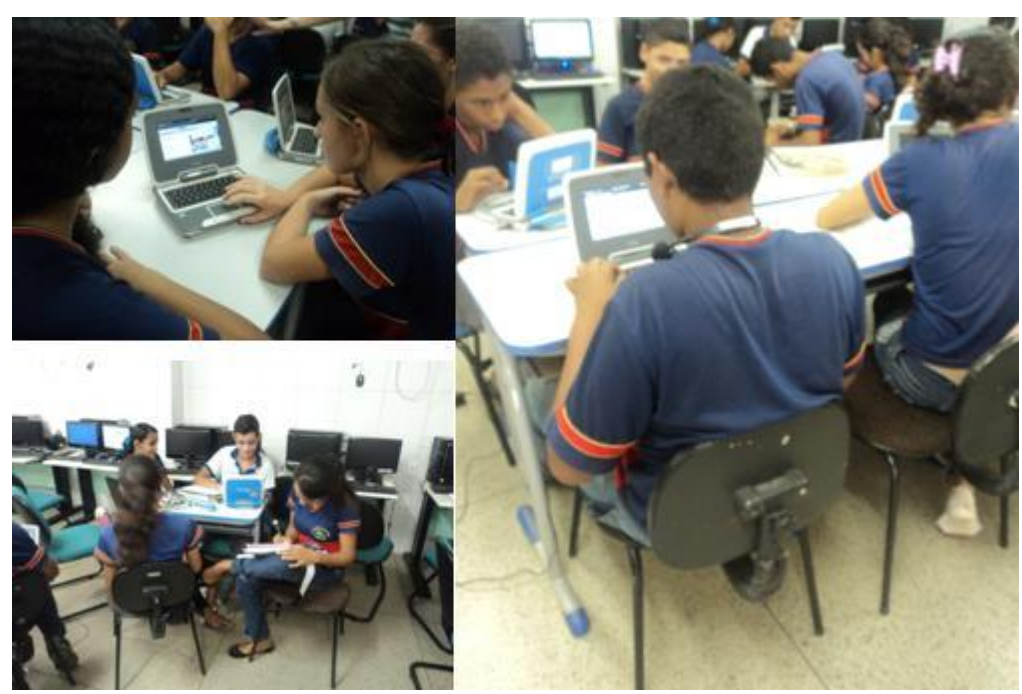

Figura 8. Alunos agrupados desenvolvendo as atividades

Um grupo de alunos desenvolveu panfletos abordando práticas educativas para a agricultura e fabricação de tijolos. Eles utilizaram os recursos do Google Maps para demonstrar os impactos ambientais causados pela população à localidade.

Os alunos também puderam perceber que o aumento da área habitada possibilitou um progresso na região, mas ao analisar aspectos geoambientais identificaram que esse progresso poderia ser melhor planejado, pois a população invade grosseiramente a área da vegetação que antes estava preservada e que agora terá que prestar contas com o meio ambiente. 
Com base nas respostas do questionário, os estudantes perceberam que a população sofre com pequenos desmoronamentos e escoamento superficial. Em épocas de grandes chuvas o rio Carás, que separa a sede do distrito do sítio Palmeirinha dos Vilar, transborda ilhando os moradores à sede e, consequentemente, ao município do Crato-Ceará.

Para conscientizar a população, os alunos organizaram um manifesto com divulgação no jornal comunitário, assim como encaminharam as ponderações feitas a respeito da pesquisa às autoridades municipais, em especial ao Secretário Municipal do Meio Ambiente.

\section{Considerações Finais}

Com base nos pressupostos do Projeto UCA de disponibilidade, conectividade e mobilidade, o laptop traz novas estratégias. A integração da tecnologia ao currículo escolar é elemento primordial para efetivação desses recursos no dia-a-dia da escola. Os recursos utilizados na própria prática pedagógica promovem nos alunos, através do uso do laptop, motivação para aprender e aplicar os seus conhecimentos no cotidiano pessoal e escolar.

Os alunos puderam constatar que a localidade em estudo está sofrendo um processo ambiental bastante complexo e merece uma análise cuidadosa por parte dos governantes locais. Além disso, utilizaram diversos recursos digitais, com o auxílio do laptop, para divulgar suas descobertas e manifestar suas opiniões sobre os impactos ambientais na região onde residem.

O estudo de caso apresentado demonstra também que o uso adequado de práticas educacionais mediadas pelos computadores portáteis pressupõe a apropriação tecnológica do educador, que, combinada com o planejamento de atividades em consonância com o currículo escolar, se configura como aspecto que vai repercutir nos modos como os estudantes serão orientados quanto ao uso dos laptops educacionais.

O planejamento das atividades e/ou projetos contribui para uma melhor utilização dos potenciais da tecnologia móvel e consequentemente favorece a aprendizagem dos alunos. Portanto, percebemos nas atividades propostas que a produção de gráficos, criação de mapas colaborativos, anotações de textos, elaboração de slides e pesquisas orientadas na Internet, partindo da própria realidade do aluno, atendem aos princípios contidos nos PCN e mais que isso, apontam na direção de conferir ao estudante um status, de sujeito que está, age e se manifesta no mundo.

Observamos também que os alunos desenvolvem estratégias de aprendizagem numa perspectiva colaborativa, coletiva e compartilhada, evidenciando ainda variáveis de aprendizagem que correspondem à autodidaxia e a colaboração.

\section{Referências}

Brasil (2000). Ministério da Educação. Secretaria de Educação Média e Tecnológica. Parâmetros Curriculares Nacionais (Ensino Médio). Brasília: MEC.

Brasil (2009). Projeto Um Computador por Aluno, UCA. Formação Brasil: Projeto, Planejamento das Ações/Cursos. Edição Núcleo de Tecnologias da Informação, UFC Virtual, Fortaleza, CE, 31 p.

Chizzotti, A. Pesquisa em ciências humanas e sociais. São Paulo: Cortez Editora, 1998. 
Lima, A. C. Jornal Ponta da Serra. (2011). Disponível em http://blogdapontadaserra.blogspot.com Acesso em 09/set/2013.

Nascimento, K. A. S. et al. (2011). Um olhar sobre a formação docente do programa UCA em uma escola municipal de Fortaleza. In: XXII Simpósio Brasileiro de Informática na Educação e XVII Wokshop de Informática na Escola. Aracaju. Disponível em http://www.br-ie.org/sbie-wie2011/WIE-Trilha2/92804_1.pdf Acesso em 09/out/2013.

Ribeiro, José C.; Lima, L. B. Mapas colaborativos digitais e (novas) representações sociais do território: uma relação possível. Revista do Programa de Pós-Graduação em Comunicação da Universidade Federal de Fluminense. Ciberlegenda: UFF, Niterói, Rio de Janeiro, 2011. Disponível em http://www.uff.br/ciberlegenda/ojs/index.php/revista/article/view/469/283 Acesso em 03/out/2013.

Santos, M. (2006). Por uma outra globalização: do pensamento único à consciência universal. Editora Record, São Paulo. Disponível em http://www.slideshare.net/BeneditoGomesRodrigues/por-uma-outra-globalizao-miltonsantos. Acesso em 09/out/2013.

Zucker, A. A. (2005). Starting School Laptop Programs: Lessons Learned. Boston. Disponível em http://ubiqcomputing.org/Lessons_Learned_Brief.pdf. Acesso em 20/set/2013. 